\title{
Noticias de Iberoamérica
}

(A cargo de Alfredo A. Roggiano, con la colaboración de Horacio J. Becco [Argentina], Hernán Díaz Arrieta ("Alone") [Chile], Luis Leal [México], Julio Icaza Tejerino [Nicaragua] y Juvenal Ortiz Saralegui [Uruguay], (Agradecemos a toda persona que nos envíe noticias para esta sección y mencionaremos aquí su nombre).

\section{ARGENTINA}

Academia Argentina de Letras. Incorporó como nuevo miembro del cuerpo académico al escritor Ricardo Sáenz Hayes. Nacido en Buenos Aires en 1888, estudió en esa Universidad y en la Escuela de Altos Estudios de París. Crítico teatral de La Prensa, representó a dicho diario en Europa. Es autor de: Almas de Crepúsculo (1909), De Stendhal a Goncourt (1923), El viaje de Anacarsis (1924), Blas Pascal y otros ensayos (1925), La Polémica de Alberdi con Sarmiento (1926), Perfiles y caracteres (1927), Miguel de Montaigne (1939) El Brasil moderno (1942), De la amistad en la vida y en los libros (1943), Miguel Cané y mi tiempo (1942), etc.

Asociación Argentina de la Crítica Literaria. A las agrupaciones con el fin de estimular la crítica literaria en la Argentina que hemos mencionado en el Núm. 41-42 (véase pág. 437) se agrega ahora este nuevo organismo, que integran figuras tan conocidas como Romualdo Brughetti, Carmen Gándara, Juan Carlos Ghiano, María Hortensia Lacau, Luis Emilio Soto y Guillermo de Torre.

A. S. C. U. A. Esta prestigiosa entidad, que continúa la tradición de Mayo en la república del Plata, ha rendido homenaje a Esteban Echeverría, con motivo de cumplirse el $106^{\circ}$ 
aniversario de su muerte. La prensa argentina divulgó en tal oportunidad una "Declaración" relacionada con el prócer y el ideario democrático que la mencionada institución defiende.

Colegio Libre de Estudios Superiores. La familia del catedrático y humanista Gregorio Halperín, fallecicio en 1951, ha creado un premio consistente en 5,000 pesos, para el mejor trabajo sobre la enseñanza del latín en la Argentina, que será otorgado por el Colegio Libre, a cuyo directorio perteneció el extinto.

Dicha institución siguió asimismo dictando cursos sobre diferentes temas de cultura, entre los que destacamos un "Homensaje a Ortega y Gasset", por la importancia del ilustre filósofo español en el desarrollo del pensamiento hispanoamericano, como lo hizo notar el profesor Francisco Romero en su magistral disertación de apertura del curso of̂recido, que tituló "Ortega y Gasset y el problema de la jefatura espiritual".

La misma institución rindió homenaje a Baldomero Sanin Cano, con motivo de su fallecimiento, con una conferencia que estuvo a cargo del Director-Editor de la Revista Iberoamericana, profesor Alfredo A. Roggiano, quien hizo un viaje de extensión cultural por distintos países de Hispanoamérica.

Baldomero Fernández Moreno. En un barrio de la ciudad de Buenos Aires, situado en la esquina de las calles Concepción Arenal y Guzmán, fue inaugurada una biblioteca popular con el nombre del gran poeta que tan bien supo evocar aspectos del vivir porteño. Asimismo, la Academia Argentina de Letras resolvió colocar una placa en la casa habitada por quien fuera miembro de dicha corporación.

Premios Literarios. La Sociedad Argentina de Escritores entregó el Gran Premio de Honor 1955 al escritor Manuel Mujica Láinez. Es ésta, sin duda la máxima recompensa honorífica que se da a un escritor argentino, y cuenta ya con una tradición que evoca nombres como los de Arturo Capdevila, Ezequiel Martínez Estrada, Victoria Ocampo y Ricardo Rojas, entre otros, a quienes también se otorgó dicho premio. Mujica Láinez es en la actualidad una de las figuras de más prestigio en las letras argentinas.

La asociación "Amigos del Libro Argentino" entregó los premios que otorga la casta editora Kraft y que se conoce 
con el nombre de "América en la novela". La recompensa asciende a la respetable suma de 30,000 pesos y fue entregada al joven novelista argentino David Viñas por su obra $U n$ Dios cotidiano.

Los premios nacionales de literatura y ciencias fueron otorgados a: Francisco Romero, por su libro Teoría del hombre; a Jorge Luis Borges, por El Aleph; a Manuel Mujica Láinez, por Los idolos; a H. A. Murena, por La fatalidad de los cuerpos; a Vicente Barbieri, por su libro poético $E l$ bailarín; a Silvina Ocampo, por Los nombres; a S. Eichelbaum, por su drama Dos brazos, a Conrado Naló Roxlo por su comedia Judith y las rosas y a P. Palant, por La dicha impia.

La Intendencia Municipal de la ciudad de Buenos Aires dispuso la creación de un gran premio, consistente nada menos que en la suma de 100,000 pesos, destinado a honrar la memoria del insigne maestro de la literatura argentina Ricardo Rojas, muerto este año. La recompensa se otorgará a la mejor obra de autor argentino editada en Buenos Aires que trate sobre temas de Indoamérica.

La misma Municipalidad otorgó los premios de literatura correspondientes a 1954-1956. Los autores favorecidos fueron: Carlos Mastronardi, H. A. Murena, Alberto Girri, Luisa Mercedes Lerensm y David Viñas.

Muertos ilustres. Tres destacados escritores argentinos murieron en el transcurso de 1957. Son ellos Luis Cané, Pedro Inchauspe y Ricardo Rojas. Luis Cané (1897-1957) era descendiente del célebre autor de Juvenilia, Miguel Cané. Excelente poeta dentro de la tradición del romancero castellano, figura en todas las buenas antologías de la poesía argentina. En 1956 se publicó en Buenos Aires un folleto titulado: "Arturo Torres Ríoseco: Luis Cané", que contiene los mejores juicios que se han emitido sobre el autor de Mal estudiante y Romancero del Río de la Plata. Pedro Inchauspe (1896-1957), redactor del diario La Prensa, es bien conocido por quienes se especializan en la literatura gauchesca argentina, tema sobre el cual ha publicado, además de su obra básica titulada La tradición y el gaucho (Buenos Aires, Editorial Kraft, 1956), un útil Diccionario del "Martín Fierro" (Edición de la "Biblioteca Manantial", Buenos Aires, 1956). Pero es indu- 
dable que la pérdida máxima que debe lamentar la República Argentina es la del Dr. Ricardo Rojas (1882-1957). Desaparecido el 29 de julio de 1957, a la edad de 75 años, deja una obra cuyo volumen alcanza, por su cantidad, calidad literaria y hondura de pensamiento, a la que realizaron los más grandes constructores de nuestra América. Fundador y primer profesor de la cátedra de literatura argentina en la Facultad de Filosofía y Letras de la Universidad de Buenos Aires, profesó en ella durante más de treinta años, hasta que en 1946 se vió obligado a retirarse por imposiciones de las circunstancias políticas de aquel momento crucial de la vida argentina. Rojas era entonces candidato a senador nacional por el partido de la Unión Democrática, el máximo oponente al avance de Perón, quien desde entonces estableció su gobierno dictatorial en el país del Plata. También perdió entonces la dirección del Instituto de Literatura Argentina de la universidad bonaerense, cuya colección de publicaciones es una de las fuentes imprescindibles para el estudio de la literatura argentina. Ricardo Rojas es el primer historiador que podríamos llamar integral de la literatura de su país. Además de su obra básica, Historia de la literatura argentina (1917-1922) fue el creador de una "Biblioteca de Autores Argentinos" y el principal orientador, hasta la fecha, de los estudios histórico-literarios hechos en su país. Militante político desde los comienzos de su carrera de escritor, conoció la cárcel en Tierra del Fuego en 1930. Decano de la Facultad de Filosofía y Letras y Rector de la Universidad de Buenos Aires, miembro de las principales academias del país y correspondiente de otras extranjeras, su personalidad ejemplar ha sido siempre motivo del más alto respeto, como pensador, como escritor de variada faceta, como figura. moral de maestro y hombre público. Historiador de la cultura nacional, descubrió símbolos que bautizó con nombres que se han acuñado definitivamente: San Martín, "El Santo de la Espada"; Sarmiento, "El Profeta de la Pampa", o bien ahondó en procesos internos y americanos que fueron hallazgos en su tiempo y que hoy constituyen corrientes de ideas fundamentales en la indagación del ser espiritual del Nuevo Mundo: La restauración nacionalista o Eurindia, por ejemplo. Su obra, 
demasiado vasta como para detallarla en esta breve nota necrológica, comprende historia, ensayo, teatro, poesía, novela, crónicas de viaje, cuentos... Sin duda mucho de ella se hace pasible de revisiones que el tiempo impondrá con crítica objetiva; pero quedará siempre la firme convicción de un ideal americanista y de argentinidad sincera y elocuente, como en todo aquel que asume una actitud, la vive, la idealiza y la defiende con pasión. Por ello la Argentina tendrá para con su maestro la deuda que siempre se tiene para con quienes han penetrado el alma de la nacionalidad. (A. A. R.).

La Revista "Nosotros". El 1' de agosto de 1957 fue recordado en Buenos Aires el cincuentenario de la fundación de la revista Nosotros. Con tal motivo se rindieron homenajes a sus fundadores, Alfredo Bianchi y Roberto F. Giusti. Alfredo Bianchi murió en 1942, y el homenaje consistió en una vista a su tumba, en el cementerio de la Chacarita, por parte de los amigos y ex-colaboradores de la revista, con el objeto de exaltar su personalidad y la importancia de su obra. Roberto F. Giusti, cuya labor como crítico literario no es necesario ponderar aquí, es el fundador y director supérstite de la valiosa publicación, y a él se le ofreció un banquete en un restaurante de Buenos Aires, al que asistió la más alta representación de la intelectualidad argentina, uruguaya y de otros países residentes en Buenos Aires. Toda la prensa argentina destacó la conmemoración como un hecho que evoca un acontecimiento trascendental en la vida cultural argentina de este siglo. Revistas de Buenos Aires y Montevideo le dedicaron artículos especiales. $\mathrm{Y}$ el mismo Roberto F. Giusti, actualmente uno de los puntales de la redacción del diario La Prensa, se encargó de evocar la historia de la revista y sus vicisitudes en un discurso que leyó en el acto de clausura de la exposición de revistas argentinas que llevó a cabo la Dirección Nacional de Cultura. EI Director-Editor de la Revista Iberoamericana, profesor Alfredo A. Roggiano, que asistió a dichos actos de homenaje, entrevistó al Dr. Roberto F. Giusti en su gabinete de estudio que actualmente ocupa en el Instituto de Literatura Iberoamericana de la Universidad de Buenos Aires. Los resultados de dicha entrevista se publican en la sección "Estudios" 
de esta revista, con el título de "Roberto F. Giusti y la revista Nosotros".

Sociedad Argentina de Escritores. A fines del mes de julio de 1957 fue elegida la nueva Comisión Directiva de dicha entidad, que agrupa a los mejores escritores argentinos. La misma quedó constituida de la siguiente manera: Presidente, Carlos Alberto Erro; Vicepresidente, Luis Emilio Soto; Tesorero, Héctor Eandi; Secretarios, Celia de Diego y Miguel Alfrerlo Olivera; Vocales, José P. Barreiro, Eduardo González Lanuza, Marcos Victoria, José Luis Lanuza, Fermín Estrella Gutiérrez, León Dujovne, Conrado Nalé Roxlo y Roberto Ledesma.

Poetas recordados. En San Martín de los Andes, Neuquén, su tierra natal, fue recordado el poeta regionalista argentino Miguel A. Camino, autor de Chaquiras y Chacayaleras y acaso el mejor poeta de la lengua en esa modalidad artística.

En Olivos, aristocrática zona del Gran Buenos Aires, el Círculo de Amigos de las Letras, las Artes y las Ciencias, recordó al poeta Fernán Félix de Amador, muerto en 1954. El autor de El ópalo encendido (1921) y La copa de David (1923) fue durante muchos años el crítico de arte del diario La Prensa.

Con otros actos similares fueron recordados: Olegario Víctor Andrade, Martiniano Leguizamón, Calixto Oyuela, Evaristo Carriego y Alfredo R. Bufano.

El conocido escritor Jorge Luis Borges fue objeto de un cálido homenaje con motivo de haber recibido el premio nacional de Literatura.

\section{BOLIVIA}

Cordillera. Acaba de publicarse el primer número de esta nueva revista boliviana de cultura; la entrega corresponde a los meses de julio-agosto de 1957. La dirige Fernando Díez de Medina, el ilustre historiador de la literatura boliviana y Ministro de Educación de aquel país. Cordillera sale a luz auspiciada por el Departamento de Publicaciones y Difusión Cultural del mencionado Ministerio de Educación. 


\section{BRASIL}

José Lins do Rego (1901-1957). Acaba de fallecer en la capital carioca el celebrado novelista, autor de Menino de en genho (1932), A moleque Ricardo; Pureza (1937), Doidinho (1933), Dangué (1934), Pedra Bonita (1939) y Fogo morto (1943). Sobre su última novela ha dicho A. A. de Melo Franco en su historia La literatura del Brasil: "Es un instintivo y su poderosa imaginación, al transportar la verdad hacia un plano de poesía y ficción, nada le resta de su fuerza elemental ni de su sabor agreste. Su última novela, Fogo morto, escrita en el mismo ambiente de las primeras, trae ya la forma más reposada de una mayor experiencia $y$, sobre todo, nos indica cualidades de penetración que no se hacían presentes en las anteriores, perdidas en caudalosa descripción".

Academia Brasileña de Letras. Eligió nuevo miembro, para ocupar la vacante de Aquino Corrêia, al conocido periodista, ensayista y autor teatral Raimundo de Magalhâes (h.).

La misma corporación ha hecho entrega de los premios correspondientes a 1956. El premio "Machado de Assis" fue otorgado a Luis da Camara Cascudo; el "Carlos de Laetes", a Adolfo Morales de los Ríos (h), y el "Coelho Neto", a Ondina Ferreira y Osman Lins.

\section{COLOMBIA}

Biblioteca Nacional. Fue designado su nuevo director, que ahora lo es el señor Julián Motta Salas.

Instituto Caro y Cuervo. Ha iniciado la publicación de una nueva serie de trabajos que lleva por título "Filólogos Colombianos". El primer volumen está consagrado a Rufino José Cuervo y lleva un estudio de Fernando Antonio Martínez y una bibliografía de José Ortega Torres.

Benigno A. Gutiérrez. Su muerte nos priva de un excelente especialista en Tomás Carrasquilla. 
442

REYISTA IBEROAMER C CANA

COSTA RICA

Luis Dobles Segrera (1890-1956). La muerte de este ilustre educador, bibliófilo y diplomático hace perder a Costa Rica uno de sus más valiosos escritores. Autor de un Indice Bibliográfico de Cosa Rica, en 9 volúmenes, y de varias obras de creación.

\section{CUBA}

Muerte de dos historiadores. Son ellos: Joaquín Llaverías (1875-1956), que fue por muchos años director del Archivo Nacional. Es autor de la Historia de los archivos de Cuba (1912) y publicó asimismo unas Cartas inéditas de José Martí (1920). El otro historiador fallecido es Gerardo Castellanos (1879-1956), autor de Ensayos biográficos (1910) y de una Historia de Santiago (1946), entre otras obras.

\section{CHILE}

Premio Nacional de Literatura. Fue otorgado a Manuel Rojas, cuya novela Hijo de ladrón, lleva ya la quinta edición: tres de la Editorial Nascimiento (1951, 1955, 1956), una de Emecé, Buenos Aires (1955) y otra de Zig-Zag (1957). Manuel Rojas nació en Buenos Aires en 1896, de padres chilenos y por eso, y por haber vivido y escrito su obra en Chile, se lo considera chileno. Sobre su obra, en general, remitimos a la Breve historia de la literatura chilena, de Arturo Torres Ríoseco (México: Manuales Studium, 1, 1956), págs. 116-118. El crítico chileno Alone nos dice de él, en carta personal: "Su personalidad simboliza muy bien la evolución literaria de Chile y la nueva faz, tan sorprendente, que ofrece nuestra cultura en este siglo, comparada con la de los siglos anteriores. No pertenece, como los autores del siglo XIX, a las altas capas sociales. Viene del pueblo, del más azotado pueblo, y se formó solo, mediante su energía íntima, su profunda y tenaz vocación, su talento vigoroso, personal, inconfundible, a espaldas de escuelas y Universidades, en una línea de tranquila avanzada. Con Hijo de ladrón la novela nacional alcanza su cumbre. 
Por eso, cuando se pregunta hoy cuál es la mejor novela chilena, juzgando por el sólo mérito literario, en el plano de las obras de arte, es preciso responder: Hijo de ladrón".

Otros Premios. El Premio "Atenea" y el premio "Mauricio Fabry" fue otorgado a José Manuel Vergara, joven de 28 años, por su novela Daniel y los leones dorados, que acaba de publicar la Editorial Pacífico. Al mismo se le otorgó también el premio de la Municipalidad de Santiago, que compartió con Enrique Délano, por su obra Puerto de fuego. El premio municipal de teatro fue otorgado a El prestamista, de Fernando Joseau y el de crítica literaria, a Mario Naudón por su obra Apreciación teatral.

Falleció Claudio Matte Pérez. A los 98 años falleció el distinguido educador Claudio Matte Pérez, autor del famoso silabario que lleva su nombre, del cual se han editado millones de ejemplares y en el que aprendieron a leer muchísimos chilenos. El extinto también era autor de muchos libros de lectura y textos de enseñanza.

Revista Literaria. La Sociedad de Escritores de Chile, presidida por Ricardo A. Latchan, ha publicado el primer número (nueva época, septiembre de 1957) de una Revista Literäria dirigida por Armando Cassigoli, administrada por René Hurtado Borne. Trae ochenta páginas de noticias, cuentos, versos; etc. y excelente material de informaciones.

Muerte de un viajero. Ha muerto Tancredo Pinochet Le Brun, escritor que vivió un poco al margen de la literatura, gran viajero, autor de Viaje Plebeyo por Europa y Viaje de Esfuerzo. Sus libros incitaron a muchos jóvenes a salir de Chile. Diarista, polemista, avanzado, independiente, hombre singular, escribió gran cantidad de obras, incluso novelas, desprovistas de calidad literaria, pero vitales. Había nacido en Santiago en $1888 \mathrm{y}$, poco antes de morir, estaba aprendiendo ruso.

Eduardo Barrios. Se han celebrado los cincuenta años de escritor de Eduardo Barrios, novelista, Premio Nacional de Literatura, cuyas novelas más famosas son Un Perdido, su mejor novela, El Hermano Asno y Gran Señor y Rajadiablos. Ha sido Ministro de Educación del Presidente Ibáñez y es Director General de Bibliotecas, Archivos y Museos. 
Octogenario. Este año cumplió ochenta de edad Diego Dublé Urrutia, autor de Fontana Cándida, colección de sus poemas. Dublé Urrutia inicia la renovación literaria del siglo, incorpora el campo chileno a la alta poesía y, con una obra escasa, ocupa la categoría máxima, indisputada hasta hoy por las nuevas generaciones.

Pablo Neruda. El gran poeta de Residencia en la Tierra y miembro del directorio de la Sociedad de Escritores de Chile, se encuentra actualmente en París.

Poeta Embajador. El poeta Juan Guzmán Cruchaga fue nombrado Embajador en El Salvador, país que designó Embajador en Chile al poeta Hugo Lindo.

\section{ESTADOS UNIDOS DE NORTEAMERICA}

Octavo Congreso del Instituto Internacional de Literatura Iberoamericana. Celebróse en Puerto Rico, tal como lo anunciamos en el Núm. 41-42 de nuestra Revista, pp. 431-434. Véase al respecto nuestro Editorial, firmado por el Dr. Arturo Torres Ríoseco.

Ralph E. Warner. Falleció inesperadamente el distinguido profesor de la Universidad de Colorado, autor de obras de investigación de primer orden en el campo de las letras hispanoamericanas, como Bibliografía de la Poesía Mexicana (Harvard University Press, Cambridge, 1934), Historia de la Novela Mexicana en el Siglo XIX (México: Editorial Robredo, 1953) y Bibliografía de Ignacio Manuel Altamirano (México: Imprenta Univeristaria, 1955). Sobre esta última publica una reseña en el número 43 de nuestra Revista, págs. 200-201, el profesor Manuel de Ezcurdia, en donde da referencias de su obra.

Luis Monguió. El destacado investigador español radicado en los Estados Unidos, ha sido incorporado definitivamente como catedrático de literatura a la Universidad de California, Berkeley. Monguió, que es uno de nuestros activos colaboradores, miembro y ex-presidente del Instituto Internacional de Literatura Iberoamericana, es autor de obras de notable mérito, como su César Vallejo. Vida y obra. Bibliografía. Anto- 
logia (New York: Columbia University. Hispanic Institute, 1952) y La poesía postmodernista peruana (Berkeley: University of California Press, 1954). Sobre este libro se publicó en nuestra Revista Núm. 40, págs. 367-376 una reseña del profesor Alfredo A. Roggiano, de la Universidad de Iowa.

Andrés Iduarte. El agudo crítico de Martí, escritor y Pláticas hispanoamericanas ha sido elegido Presidente del Instituto Internacional de Literatura Iberoamericana por el período 1957-1959. Iduarte, mexicano de origen, es actualmente profesor de la Columbia University, en New York.

Próximo Congreso. El próximo congreso del Instituto Internacional de Literatura Iberoamericana, o sea el noveno, se realizará en New York y New Brunswick (New Jersey) y. será patrocinado por las Universidades de Columbia y Rutgers.

\section{MEXICO}

Nuevo académico. El 14 de junio de 1957, en el salón de actos de la Academia Mexicana de la Lengua, correspondiente de la española, leyó su discurso de ingreso el novelista Mauricio Magdaleno, autor de El Resplandor y otras conocidas novelas. Su disertación versó sobre "El compromiso de las letras".

Alejandro Quijano (1883-1957). Falleció en la ciudad de México el 17 de febrero. Desde 1939, al perecer don Federico Gamboa, había ocupado el puesto de presidente de la Academia Mexicana de la Lengua. A él se debió la organización del primer Congreso de Academias de la Lengua Española, que se celebró en la ciudad de México. Por largo tiempo fue director del diario Novedades. Atildado escritor, demostró su interés en la lengua con sus obras Cervantes y el Quijote en la Academia (1935) y Los diccionarios académicos (1940).

Alfonso Reyes. El 17 de mayo de 1957 el jlustre escritor tomó posesión de la presidencia de la Academia Mexicana de la Lengua.

Rómulo Gallegos. El 20 de agosto de 1957 el novelista venezolano leyó en la sala Manuel M. Ponce del Palacio de 
Bellas Artes, en la ciudad de México, los tres primeros títulos de su nueva novela La brasa en el pico del cuervo, de tema mexicano, todavía inédita.

Teatro. La temporada teatral del Instituto Nacional de Bellas Artes para el verano de 1957, en el Teatro Ródano, fue dedicada exclusivamente a la presentación de piezas de autores mexicanos. La primera obra que se presentó fue la comedia Felicidad, de Emilio Carballido, joven dramaturgo veracruzano autor también de Las palabras cruzadas (1955) y La hebra de oro (1956).

Antonio Mediz Bolio (1884-1957). Falleció en la ciudad de México el 15 de septiembre. Fue poeta, dramaturgo y autor de leyendas. Su obra más conocida es la colección de leyendas sobre Yucatán, La tierra del faisán y del venado (1922), en la cual demuestra su extraordinario amor a la patria chica.

Primer Congreso Panamericano de Teatro. Celebróse en México del 12 al 15 de octubre ppdo. con la asistencia de delegados de países. Celestino Gorostiza y Bernardo Reyes fueron el presidente y el secretario del mismo.

\section{NICARAGUA}

Julio Icaza Tejerino. Nuestro colaborador y corresponsal en Nicaragua, Dr. Julio Icaza Tejerino, escritor y jurisconsulto, ha sido elegido Diputado Nacional. Icaza Tejerino, excelente crítico y escritor ágil en obras como Originalidad de Hispanoamérica (Madrid: Ediciones Cultura Hispánica, 1952), ha obtenido el Primer Premio Nacional "Rubén Darío" por su obra La Poesía y los Poetas de Nicaragua.

Premio de Poesia. El Premio Nacional de Poesía "Rubén Darío" fue otorgado a Luis Alberto Cabrales.

\section{URUGUAY}

Jornadas Poéticas. Del 11 al 17 de marzo último se desarrollaron en el Balneario de Piriápolis, las Primeras Jornadas Interamericanas de Poesía, a las que concurrieron 78 poetas, la 
mayoría del Río de la Plata. La delegación argentina estuvo integrada por cerca de treinta, entre los cuales figuraban Ricardo E. Molinari, Carlos Mastronardi, Amelia Biagioni, Emma de Cartosio, Córdova Iturburu, Eduardo González Lanuza y Horacio Esteban Ratti. Del Uruguay: Pedro Leandro Ipuche, Carlos Sábat Ercasty, Vicente Basso Maglio, Enrique Casaravilla Lemos, Juvenal Ortiz Saralegui, Arsinoe Moratorio, Walter González Penelas, etc. De Ecuador, Leopoldo Benítez Vinueza; de Chile, Julio Moncada; de Bolivia, Raúl Botelho Gosálvez y Guillermo Vizcarra Fabre y de Brasil, dos riograndenses, Pedro Gerardo y Héctor Saldaña. Hubo debates sobre poesía y actos de homenaje a Julio Herrexa y Reissig (que viviera en el Castillo de Piria, fundador del balneario) y a Gabriela Mistral.

Premios. El Ministerio de Instrucción Pública ha convocado a los Jurados Literarios para la producción de los años 1954 y 1955, que funcionan en estos momentos. Hasta la fecha fueron otorgados dos premios 1954 al ensayo: a Alberto Zum Felde por su obra Indice Crítico de la Literatura Hispanoamericana. El ensayo y la crítica y a Francisco Espíndola por Milón o El Ser del Circo.

Asociación Uruguaya de Escritores. Fue designado nuevo presidente el conocido novelista Adolfo Montiel Ballesteros, autor de Querencia, Gaucho tierra, Mundo en ascuas y otros originales libros de cuentos y novelas.

Colección Poética. Los "Cuadernos Julio Herrera y Reissig" en 1957 han editado: Fábula del Cielo, poemas por Mariano Olivera Ubios; Sonetos a una Rosa Blanca por Uruguay González Poggi; Torre de Otoño, poemas por Juvenal Ortiz, Saralegui; Melodías del Silencio, poemas en prosa por Eugen Relgis y en breve aparecerá Paradoja de la Imagen, poemas por Humberto Zarrilli.

Homenaje a Julio J. Casal. Julio J. Casal, el inolvidable poeta desaparecido el 7 de diciembre de 1954, fue objeto de un homenaje de la ciudad de Montevideo, descubriéndose en los jardines del frente del Museo Municipal de Bellas Artes "Juan Manuel Blanes" una piedra con la siguiente leyenda grabada: "El Municipio de Montevideo, los escritores y artis- 
tas uruguayos dedican este árbol al poeta Julio J. Casal. 18-VI1889-7-XII-1954". La piedra contiene además este poema de Casal:

$$
\begin{aligned}
& \text { Cuando acaso regreses } \\
& \text { al ultimo viaje } \\
& \text { de acogedora tierra, } \\
& \text { me encontrarás al fin } \\
& \text { en un temblor de hoja } \\
& \text { que mecerá tu sueño... }
\end{aligned}
$$

En la ceremonia, que alcanzó singular brillo, disertó la vice-Presidenta del Municipio, poetisa Alba Roballo, la poetisa Arsinoe Moratorio y el Embajador de Ecuador Lic. Leopoldo Benítez Vinueza.

Disertantes Argentinos y Uruguayos. Han dictado conferencias en Montevideo los escritores argentinos Jorge Luis Borges, Roberto F. Giusti, Antonio Pagés Larraya y Córdova Iturburu.

En el departamento cultural de "La Razón" de Buenos Aires, Juvenal Ortiz Saralegui dio una conferencia sobre poesía uruguaya, interviniendo con lectura de poemas Gladys Burci, Luis Alberto Caputi, Uruguay González Poggi y Mariano Olivera Ubois. 